\title{
RUZ BARRIO Miguel Ángel y Juan José BATALLA ROSADO (coord.), Los códices mesoamericanos. Registros de religión, política y sociedad
}

\section{Antonio Jaramillo Arango}

\section{(2) OpenEdition}

Edición electrónica

URL: https://journals.openedition.org/jsa/16613

DOI: 10.4000/jsa.16613

ISSN: 1957-7842

Editor

Société des américanistes

\section{Edición impresa}

Fecha de publicación: 15 diciembre 2018

Paginación: 235-237

ISSN: 0037-9174

\section{Referencia electrónica}

Antonio Jaramillo Arango, «RUz barRio Miguel Ángel y Juan José Batalla RoSAdo (coord.), Los códices mesoamericanos. Registros de religión, política y sociedad», Journal de la Société des américanistes [En línea], 104-2 | 2018, Publicado el 15 diciembre 2018, consultado el 04 septiembre 2022. URL: http:// journals.openedition.org/jsa/16613 ; DOl: https://doi.org/10.4000/jsa.16613

Este documento fue generado automáticamente el 4 septiembre 2022.

All rights reserved 


\title{
RUZ BARRIO Miguel Ángel y Juan José BATALLA ROSADO (coord.), Los códices mesoamericanos. Registros de religión, politica y sociedad
}

\author{
Antonio Jaramillo Arango
}

\section{REFERENCIA}

RUZ BARRIO Miguel Ángel y Juan José BATALLA ROSADO (coord.), Los códices mesoamericanos. Registros de religión, política y sociedad, El Colegio Mexiquense, Zinacantepec, 2016, 342 p., bibliogr., ill. en blanco y negro, fotos en blanco y negro, mapas.

1 Editado por el Colegio Mexiquense, el libro Los códices mesoamericanos. Registros de religión, política y sociedad es una compilación de artículos coordinada por los investigadores españoles Miguel Ángel Ruz Barrio y Juan José Batalla Rosado. El libro recopila doce textos derivados de investigaciones con alcances disímiles, como los mismos coordinadores de la obra admiten en su introducción, pues entre los colaboradores se encuentran especialistas consolidados y colegas que apenas comienzan su carrera. Esto no mina la calidad de la obra en su conjunto; muy por el contrario, el lector se encontrará con una diversidad de posturas sobre la investigación de los códices que incluye la revisión de argumentos tradicionales, la exploración de documentos poco o nada conocidos, perspectivas novedosas de análisis e intuiciones a ser desarrolladas en el futuro.

2 Se conocen como "códices mesoamericanos" a los documentos en soporte flexible (papel, piel de animal o tela) que contienen restos de pictografía o escritura indígena. Este libro analiza este tipo de documento histórico desde la perspectiva particular de cada autor. De esta forma, los artículos están agrupados en tres ejes temáticos: 1. El 
sistema de comunicación gráfica en los códices, 2. Cosmovisión y religión en los códices mesoamericanos, y 3. Política, sociedad y economía en los códices.

El primer bloque discute la metodología de interpretación y lectura de los códices derivada de distintas tradiciones. Tatiana Valdéz Bubnova explora el posible origen teotihuacano de ciertas temáticas presentes en el Códice Borgia. Por su parte, Gordon Whittaker resalta la importancia del conocimiento histórico, geográfico y contextual a la hora de leer los conjuntos glíficos nahuas más allá del "desciframiento" de elementos aislados. Los dos artículos restantes de la sección analizan casos específicos de lecturas e interpretaciones de algunos elementos en los códices. Isabel Bueno señala la dificultad de descifrar los glifos asociados con personajes en una sección del Códice Telleriano Remensis y analiza las diferentes interpretaciones académicas sobre ese fragmento. En un magnífico análisis, Katarzyna Mikulska utiliza fuentes escritas, iconográficas y lingüísticas para desentrañar la polivalencia de las banderas (de algodón y de papel) en los códices provenientes del centro de México.

Dedicado a la "cosmovisión", el segundo bloque del libro analiza ciertos elementos dentro de los códices. Nathalie Ragor caracteriza a Chicomecóatl, diosa del Posclásico del centro de México, según los rasgos con los que aparece en diferentes códices y fuentes escritas de la colonia temprana. Siguiendo una metodología diferente, Marta Gajewska analiza a la diosa Tlazoltéotl no según las características formales mediante las cuales es representada, sino siguiendo la función que cumple como patrona de la trecena ce ollin en el Códice Telleriano Remensis y el Códice Vaticano A. Por último, Miguel Ángel Ruz Barrio estudia las apariciones de murciélagos en diversos códices mánticos y administrativos.

5 Correspondiente a la política, la economía y la sociedad, la última sección es la más lograda del volumen y cuenta con los trabajos más sólidos. El primer artículo, a cargo de Carlos Santamarina Novillo, toma el ejemplo de Cuauhtitlan para estudiar las estrategias políticas de dominación de dos imperios del centro de México: el tepaneca de Azcapotzalco y el mexica de Tenochtitlan. En un trabajo corto, pero muy cuidado, María Teresa Jarquín Ortega contextualiza el códice Osuna en el marco de los reclamos indígenas del siglo xvi en la Ciudad de México por la explotación de la cal y su uso en las construcciones españolas. Por su parte, Manuel A. Hermann Lejarazu estudia la genealogía colonial de Jaltepec en la Mixteca Alta, mostrando sus diferencias con los documentos de este tipo de origen prehispánico y contextualizando los datos en un pleito legal entre dos ramas de una misma familia. En un excelente análisis, Bérénice Gaillemin muestra asimismo la forma en que uno de los documentos, clasificado dentro de los Testerianos (catecismos pictográficos dirigidos a un público indígena), fue utilizado en una fecha posterior a su manufactura por parte de un miembro de la familia heredera de Moctezuma para probar su pertenencia a este linaje y, a la vez, mostrarse como buen cristiano. Finalizando la sección se encuentra el artículo de Hans Roskamp, quien despliega un panorama general de los títulos primordiales de Michoacán, exponiendo la temática histórica general de este tipo de documentos a través de ejemplos conocidos e inéditos.

6 Más allá de la variedad temática en que los coordinadores ordenan las contribuciones y de la diferencia en el calado de las investigaciones presentadas, resalta la diversidad metodológica de los autores del libro al acercarse a los códices como fuentes históricas. Algunas contribuciones se centran en un solo elemento de uno o dos códices determinados (Bueno, Gajewska), otras analizan un cierto elemento en varios 
documentos (Mikulska, Ragot, Ruz Barrio), algunos autores toman información contenida en los códices y la utilizan críticamente para compararla con otro tipo de fuentes (Santamarina Novillo) mientras que otros toman un solo documento y analizan su contexto social, político y económico (Jarquín Ortega, Hermann Lejarazu, Gaillemin); además, surgen posibilidades de examinar todo un grupo de documentos (Roskamp) o bien de realizar reflexiones metodológicas que sirvan para el análisis de una gran cantidad de códices (Valdez Bubnova, Whittaker). No existe pues un solo camino en el estudio de los códices, y esta compilación demuestra que el diálogo y la discusión entre perspectivas distintas es la forma más fértil de analizar históricamente este tipo de fuentes.

7 En fin, la diversidad metodológica en el estudio de los códices que expone esta compilación nos demuestra la riqueza de este tipo de documentos como fuentes históricas y la multiplicidad de opciones y perspectivas que tienen los investigadores a la hora de integrar los códices en sus análisis históricos e historiográficos. Aunque este libro no pretende agotar la diversidad temática y metodológica del estudio de los códices, sí resaltan por su ausencia los trabajos sobre códices provenientes del área maya, sean prehispánicos o coloniales, como también sobre los diferentes códices mixtecos precoloniales. Sería bastante provechosa una discusión amplia, como la que propone esta compilación, que incluyera además esos documentos.

\section{AUTORES}

\section{ANTONIO JARAMILLO ARANGO}

Instituto de Investigaciones Históricas, Universidad Nacional Autónoma de México 